\title{
Assessing the Surface Rainwater Harvesting Potential for Abuja, Nigeria: A Short-term Projection
}

\author{
E. Ohiambe ${ }^{1 *}$, P. G. Home ${ }^{1}$, A. O. Coker ${ }^{2}$, J. Sang ${ }^{1}$ \\ ${ }^{1}$ Pan African University of Basic Science, Technology and Innovation, Jomo Kenyatta University of \\ Agriculture \& Technology, Nairobi, Kenya. \\ ${ }^{2}$ Department of Civil Engineering, University of Ibadan, Ibadan, Nigeria.
}

\begin{abstract}
This study aimed at assessing the surface rainwater harvesting potential in Abuja as a means of mitigating the problem of water scarcity. Surface rainwater harvesting potential for the year 2046 was assessed using Geographical Information System (GIS) and Spatial Multi-criteria Evaluation (MCE). The criteria considered were annual rainfall, land use/land cover (LULC), slope and soil. The spatial MCE was used to estimate the extent of surface rainwater harvesting and rank the potential. Analytical Hierarchy Process (AHP) was employed to determine the priority weights of the criteria which gave; rainfall 55.9\%, LULC 26.3\%, slope $12.2 \%$ and soil 5.7\%. A potential map for surface rainwater harvesting was produced showing moderate, good and excellent with the percentages of Abuja 10.7, 34.4 and 54.9\% respectively. After considering an increased rainfall from (1170 mm-1470 mm) in 2016 to $(1230 \mathrm{~mm}-1910 \mathrm{~mm})$ in 2046, expansion in built-up areas, bare surfaces due to urbanisation and population growth, the result showed that Abuja will have a minimum of 5.8 billion litres of water harvestable from rainfall per year which is about $14.8 \%$ increase compared to the estimated harvestable quantity for 2016 . Therefore, the potential for surface rainwater harvesting in 2046 is significantly greater than it was in 2016.
\end{abstract}

KEYWORDS: Surface Rainwater Harvesting Potential, Water Scarcity, Analytical Hierarchy Process, Multi-Criteria Evaluation.

[Received May 14, 2018; Revised September 07, 2018; Accepted September 27, 2018] Print ISSN: 0189-9546 | Online ISSN: 2437-2110

\section{INTRODUCTION}

Water is an important resource in every area of life, it is essential for all aspects of life ranging from agriculture to commerce, manufacturing and several types of energy including electrical energy. The existence of humans, animals and plants is solely dependent on water (Pandey et al., 2003; Rutherford, 2000). As important as water is, it cannot be manufactured yet it can be polluted, recycled, desalinated or treated (Eletta et al., 2018). Even though water is never lost, different parts of the world are experiencing water scarcity as a major environmental problem (Mahmoud and Alazba, 2014).

Water scarcity is an inequality of supply in response to demand for water with respect to existing institutional arrangements and prices; where demand is excessively high compared to available water supply; especially if the supply potential is difficult or expensive to tap (Stratfor, 2018; Food and Agriculture Organisation, 2010; Kisakye et al., 2018). Water scarcity can be caused by artificial and natural causes. The artificial causes are basically human activities and behavior while natural causes include geographical terrain and climate (Eletta et al., 2018; Stratfor, 2018). In Nigeria water scarcity problem is also prominent especially in the ASAL regions which are situated in the northern part of the

*Corresponding author: ohiambeeseoghene@yahoo.com country. However, the water scarcity issue in Abuja is unique because Abuja is not classified as an ASAL region. In fact, Abuja actually experiences an average annual rainfall of about $1100 \mathrm{~mm}-1600 \mathrm{~mm}$ and its temperatures are not as high as the ASAL regions. But, the population growth in Abuja has been very rapid within a short period. The population grew from 107,069 in 1991 to $2,238,800$ in 2011 which is only 20 years and has grown even more to 3,564,100 in 2016. Urbanization has led to a lateral expansion of the cities which is leading to a higher demand for water, strain on the existing water sources and distribution systems. In recent times, both urban and rural areas in Abuja have suffered from water scarcity, this is because the rate at which the available water is consumed is significantly greater than the rate at which the tapped sources are replenished.

During the Pan-African Conference on Water in Addis Ababa, 2003, and at the African MDGs on Hunger meeting in 2004, rainwater harvesting was identified as an important way of meeting the African Water Vision of minimizing water scarcity and reducing poverty (Maimbo et al., 2005). In Abuja, since the problem of water scarcity is as a result of an increase in population and expansion of the cities and towns, rainwater harvesting would be ideal as it will provide water close to where it is needed. Rainwater harvesting is the systematic concentration, collection and storage of rainwater doi: http://dx.doi.org/10.4314/njtd.v16i2.3 
and surface runoff for different uses by linking the collection area or runoff catchment area with the storage facility or runoff receiving area (Mbilinyi et al., 2005). Rainwater harvesting is not a new concept, it is an ancient practice which can be traced back thousands of years BC. Harvested rainwater was used for many purposes, including drinking (both for animals and humans alike), domestics, agricultural, prevention of environmental issues like minimize risk of drought ASAL areas, flooding, erosion (Intergovernmental Panel on Climate Change, 2007). It was also used as a means for groundwater recharge (Rainwater Harvesting, 2006; Rutherford, 2000). Rainwater harvesting is being encouraged and promoted in many countries including China, Brazil, Australia and India.

In New Delhi and Chennai, India, it is mandatory to have a rainwater harvesting plan for a building plan to be approved. Rainwater can be harvested through several mediums, all of which can be summed into three major categories; roof tops, surface and in-situ rainwater harvesting (Gould and Nissen-Peterson, 1999; Maimbo et al., 2005). Surface rainwater harvesting provides natural soft water which can serve all non-potable water usages. It involves the collection of runoff from open surfaces such as roads, home compounds, hillsides, rocks, open pasture lands, bare grounds (Gould, 1992; Pacey and Cullis, 1989). It may also include collecting runoff from water courses and gullies. It is an intervention that could be implemented almost anywhere and by anyone; however, it would be better implemented by governmental bodies so that it can be done in large scales to collect more water from strategic locations. To harvest rainwater the climatic conditions of a place should be studied and understood (Gould and Nissen-Peterson, 1999).

The present climatic condition of Abuja is such that rainwater harvesting can be implemented effectively. However, climate change might affect rainfall in Abuja either positively or negatively. Climate change is a change in the statistical distribution of weather patterns usually over a short-term period of at least 30 years (Australian Academy of Science, 2018). The Global climate change estimates show a variation in weather patterns but most of the estimates concur that some areas will have increased precipitation while others will experience a drought (Kisakye et al., 2018). A short-term projection of the climate change in Abuja will help to estimate if the change will affect RWH potential positively or negatively.
Therefore, the objective of this research was to assess the surface rainwater harvesting potential in Abuja by considering the short-term (at least 30 years), in which significant change in climate and land use/land cover could occur. The aim is to inform decision makers of an additional source of water to minimize water scarcity and ultimately balance the existing imbalance between supply and demand of water in Abuja. This can be done by assessing and highlighting potential sites for surface RWH. The selection of potential areas depends on several factors including climate, hydrology, topography, soils, socioeconomic criteria even agronomy as highlighted. Mahmoud and Alazba (2014) citing Kahinda et al. (2008). Several studies have used different parameters. Mahmoud and Alazba (2014) used soil texture, elevation, land use/land cover, slope, rainfall surplus and potential runoff coefficient to identify in-situ rainwater harvesting potential in Al-Baha, Saudi Arabia. Kahinda et al. (2008) used soil texture, soil depth, rainfall, land cover ecological importance to produce suitability maps for in-field and ex-field rainwater harvesting.

Multi-Criteria Evaluation (MCE) plays a significant role in life-problems, at some point almost every organization from private to public sector are involved in the evaluation of alternatives in decision making especially with conflicting criteria (Udezo, 2017). Analytical Hierarchical Process (AHP) is a MCE tool introduced by Saaty (1980). It is one of the GIS databased MCE which sums and transforms spatial data to a result decision (Mahmoud and Alazba, 2014). AHP is the major decision-making tool employed in this study. Weighted overlay tool is also another relevant for the selection of potential sites for surface RWH. The overlay process produces maps with ranks from 1-5 where 1 is the lowest and 5 is the highest rank. However, some researchers have classified these ranks using terms like unsuitable, suitable, low, high, medium, moderate, poor, excellent (Mahmoud and Alazba, 2014; Kahinda et al., 2008; Maimbo et al., 2005).

\section{MATERIALS AND METHODS}

\section{A. Study Area}

Abuja is located in the North Central zone, at the center of Nigeria just north of the confluence of the Niger and Benue River with a total land area of $7,315 \mathrm{~km}^{2}$. Abuja, also known as Federal Capital Territory (FCT) has six local

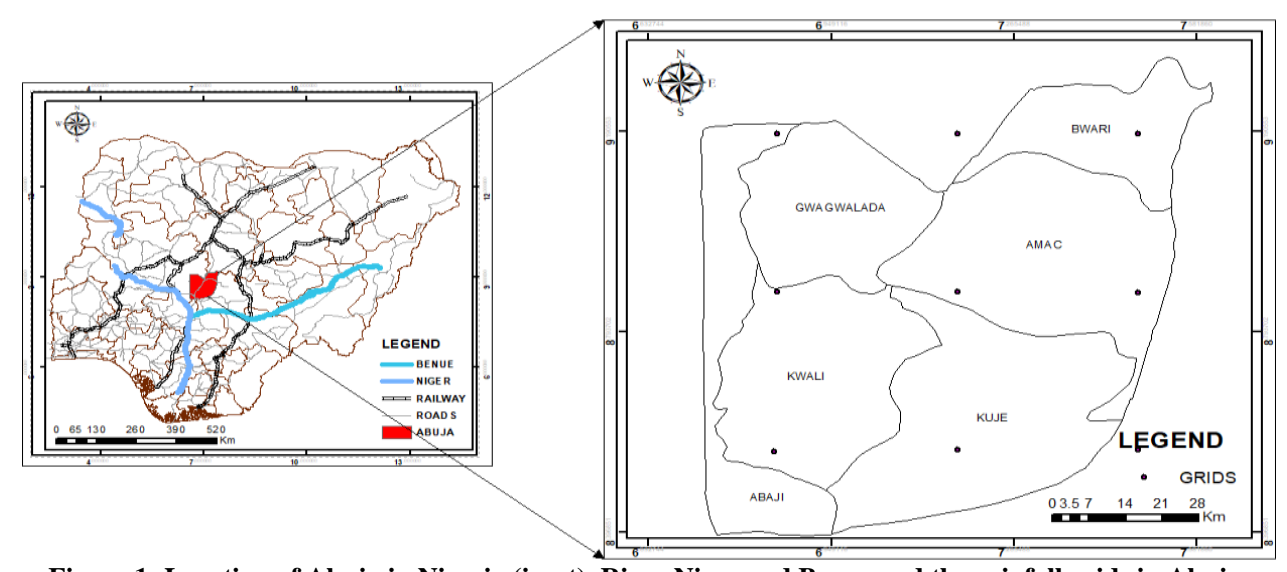

Figure 1: Location of Abuja in Nigeria (inset), River Niger and Benue and the rainfall grids in Abuja. 
government areas; Abaji, Bwari, Gwagwalada, Kwali, Kuje and Abuja Municipal as shown in (Figure 1). Abuja lies between the range of 300-760 $\mathrm{m}$ above sea level, the highest part of Abuja is in the northeast where there are major peaks some above $760 \mathrm{~m}$. Abuja has three distinct weather conditions per annum; a warm, rainy season, a hot dry season and a short period of harmattan between the rainy and dry season. The rainy season begins in April till October, with temperatures reaching about $28^{\circ}-30^{\circ} \mathrm{C}$ in the day and temperatures range around $22^{\circ}-23^{\circ} \mathrm{C}$ at night, the total annual rainfall is about $1100 \mathrm{~mm}$ to $1600 \mathrm{~mm}$ making it a potentially good region for rainwater harvesting. During the dry season, daytime temperatures can increase to $40^{\circ} \mathrm{C}$ and night temperatures sometimes drop to $12^{\circ} \mathrm{C}$ (Cyblug, 2016).

\section{B. Assessing the RWH Potential of Abuja}

The criteria necessary in assessing the potential of RWH are; rainfall data, land use maps, elevation maps, soil maps (Maimbo et al., 2005; Mahmoud and Alazba, 2014). To assess the surface RWH potential in the study area, the following activities were carried out;

\section{1) Rainfall forecast}

The rainfall data is a relevant component in estimating the rainwater harvesting potential for Abuja, however, in order to estimate the rainwater harvesting potential for the range of years 2046-2065, there must be a forecast of the climatic conditions expected at that time. In this study, the rainfall forecasted data was directly collected from the World Bank Climate Change Portal (WBCCP) where the forecasting had already been done. With the data, a spatial representation of the rainfall was done on GIS using the Interpolated Distance Weighted (IDW) which according to Mahmoud and Alazba (2014) is a suitable method for the spatial representation of rainfall. The extent was set to fit the study area and the rainfall grids shown in Figure 1.

\section{2) Slope data}

The Shuttle Radar Topography Mission (SRTM) 30m DEM of the study area was obtained from United State Geological Survey/National Aeronautics and Space Administration/Shuttle Radar Topography Mission (USGS/NASA SRTM). The slope ranges were reclassified into four $\left(0-5^{\circ}, 5.1-10^{\circ}, 10.1-19^{\circ}\right.$ and $\left.19.1-71.9^{\circ}\right)$ like Mahmoud and Alazba (2014) giving a view of the flat, moderate, steep and hilly regions in the study area using their rise in degrees. This data is assumed to remain constant and so was not be projected.

\section{3) Land use/Land cover data}

In this study the Landsat imagery was used to create the land use/land cover (LULC) map for the study area. The spatial resolution $30 \mathrm{~m}$ of Landsat imagery is adequate for vegetative analysis particularly, to identify vegetative cover (Jonathan et al., 2017). Two scenes of Landsat images from the Landsat7 and Landsat8 were acquired for the LULC of the years 2001 and 2016 respectively. These were all obtained online from the data archive of Global Land Cover Facility (GLCF) under the United States Geological Survey (USGS). The images acquired for the use of this study were cloud free. The land use/land cover maps for the years 2001 and 2016 were created using the maximum likelihood algorithm for supervised image classification on ERDAS Imagine 2014 after forming a false color composite with bands 4, 3 and 2 which are the infrared, red and blue bands respectively. The image classification gave nine different classes which helped to assess the changes in land use over 15 years (2001-2016).

\section{4) Land use/land cover projection}

LULC is an important component of the study of rainwater harvesting as stated by Maimob et al. (2005) and especially for this study because surface rainwater harvesting technologies are dependent on the different land use and land cover classifications. In this study, the LULC of the years 2001 and 2016 was used to aid the projection of the LULC for the year 2046. After creating the LULC maps for 2001 and 2016, the Markov model on IDIRISI change was adopted to produce the LULC for 2046 and the area occupied by each LULC was calculated using the area calculator on IDIRISI. Markov model is a reliable tool for simulating LULC change in situations where changes and processes in the LULC prove to be complex to describe (Logsdon, 1996).

A Markov process is one in which the later state of a system can be defined simply by the immediately preceding state. This is done by creating a transition probability matrix for LULC change from one time to the next time. It shows the characteristics of the change as well as serves as the foundation for projecting to a future time-period (Dongjie et al., 2008; Zhang et al., 2011; Huang et al., 2008; Muller and Middleton, 1994). Markov model gives a simple methodology with which a dynamic system can be dissected and explained. Several researchers like Zhang et al. (2011) and Jianping et al. (2005) have attested to the efficiency of the Markov model.

\section{5) Soil data}

The soil map for Abuja was obtained from Harmonised World Soil (HWS) database. There exist five soil types in Abuja which are loam, sand, loamy sand, sandy clay and sandy loam as stated by Kogbe (1978). The composite runoff coefficient for different soil types in relations to slope and land use was calculated using the information for runoff coefficient given by Mohamed et al. (2014).

Composite runoff coefficient is given as;

$C=\frac{C_{1} A_{1}+C_{2} A_{2}+\cdots C_{n} A_{n}}{A_{\text {total }}}$

where: $C$ is the composite runoff coefficient

$C_{1}$ to $C_{n}$ are the corresponding runoff coefficients for different landuses, soil type or slope

$A_{l}$ to $A_{n}$ are corresponding areas of different landuses, soil types or slopes

$A_{\text {total }}$ is the sum of the areas considered from $\mathrm{A}_{1}$ to $\mathrm{A}_{\mathrm{n}}$ (Odot Hydraulics Manual) 


\section{6) Application of the analytical hierarchical process (AHP)}

The Analytical Hierarchy Process (AHP) developed by Saaty (1980) is a method used for analyzing and supporting decisions in which several competing objectives are involved with multiple available alternatives. The technique was used on the basis of three principles: decomposition thereby forming a hierarchy of decision, comparative judgment and combination of priorities (Saaty, 1980).

The AHP and weighted overlay for assessing the surface RWH potential was done using Saaty's pairwise comparison scale. The hierarchy is the final goal which is to determine the potential for surface RWH. The next stage in the hierarchy is the criteria needed to determine the potential. For this study, the criteria used are rainfall, soil, slope and LULC. The ranking in this stage helps to reclassify each of the criteria maps into their different ranks. The advantage of this hierarchical decomposition is simply to clearly understand the decisions as well as results to be obtained, the criteria to be used and the alternatives present (Decision Lens, 2015).

\section{Determining Priorities Weight for each Criteria}

The rainfall, LULC, slope and soil as determinant criteria for rainwater harvesting potential are of different importance. The second step in the AHP process is to determine the relative weight of each criteria. This is called relative weight because the derived criteria priorities are measured with respect to each other.

\section{1) Pairwise comparison for surface $R W H$}

This is the comparison between the criteria used for the analysis. Table 1 shows the pairwise comparison matrix of the criteria for surface RWH. The weight of each criterion is obtained using the normalized matrix generated from Table 1. The average value of each row in the normalized matrix is the weight.

The second stage is the calculation for the weight of each criterion used in the pairwise comparison. It is obtained by summing up the values in each column, a normalized matrix is formed by dividing each value in the pairwise comparison matrix by the total of its column as shown in Table 2 .

Table 1: Pairwise judgment matrix and weights.

\begin{tabular}{lllll}
\hline Surface RWH & Soil class & Slope class & LULC class & Rain class \\
\hline Soil class & 1 & 0.33 & 0.2 & 0.14 \\
Slope class & 3 & 1 & 0.33 & 0.2 \\
LULC class & 5 & 3 & 1 & 0.33 \\
Rain class & 7 & 5 & 3 & 1 \\
Column addition & 16 & 9.33 & 4.53 & 1.67 \\
\hline
\end{tabular}

Table 2: Normalized Matrix.

\begin{tabular}{llllll}
\hline $\begin{array}{l}\text { Surface } \\
\text { RWH }\end{array}$ & $\begin{array}{l}\text { Soil } \\
\text { class }\end{array}$ & $\begin{array}{l}\text { Slope } \\
\text { class }\end{array}$ & $\begin{array}{l}\text { LULC } \\
\text { class }\end{array}$ & $\begin{array}{l}\text { Rain } \\
\text { class }\end{array}$ & Weight \\
\hline Soil class & 0.0625 & 0.0354 & 0.0442 & 0.0838 & 0.0565 \\
Slope class & 0.1875 & 0.1072 & 0.0728 & 0.1198 & 0.1218 \\
LULC class & 0.3125 & 0.3215 & 0.2208 & 0.1976 & 0.2631 \\
Rain class & 0.4375 & 0.5359 & 0.6623 & 0.5988 & 0.5586 \\
\hline
\end{tabular}

\section{2) Consistency}

Once judgment is made and the criterion weights obtained, it is important to verify the consistency of the judgment made. This is illustrated below.

a) Start with the matrix showing the judgment comparisons and derived weights which is presented in Table 1.

b) Use the weights as factors (priority) for each column.

c) Multiply each value in the first column of the pairwise comparison matrix in Table 1 by the first criterion weight (i.e., $1 \times 0.0565=0.0565 ; 3 \times 0.0565=0.1694$; $5 \times 0.0565=0.2823 ; 7 \times 0.0565=0.3952$ ) multiply each value in the second column with the second weight; continue this process for all the columns of the comparison matrix (in our case, we have four columns).

d) Add the values in each row to obtain a set of values called the weighted sum

e) Divide the values of the weighted sum vector (obtained in the previous step) by the corresponding weight of each criterion. Calculate the average of the values from the previous step; this value is called $\lambda_{\max }$.

$$
\lambda_{\max }=(4.0290+4.0203+\ldots .4 .2109) / 4=4.1057 .
$$

f) Then we calculate the consistency index (CI) as follows:

$$
\mathrm{CI}=\left(\lambda_{\max }-\mathrm{n}\right) /(\mathrm{n}-1)
$$

Where $\mathrm{n}$ is the number of compared elements (in this example $n=4$ ).

Consistency index is therefore, $\mathrm{CI}=\left(\lambda_{\max }-\mathrm{n}\right) /(\mathrm{n}-1)=(4.1057-4) /(4-1)=0.0352$

g) Now, the Consistency Ratio can be calculated thus:

$$
\begin{aligned}
& \mathrm{CR}=\mathrm{CI} / \mathrm{RI} \\
& \mathrm{CR}=0.0352 / 0.9=0.0396
\end{aligned}
$$

where the Random Index (RI) is 0.89 for $n=4$ given by Saaty (1980) and Mahmoud \& Alazba (2014).

Since this value (0.0396) for the proportion of inconsistency CR is less than 0.10 , we can assume that our judgments matrix is reasonably consistent, so we may continue the process of decision-making using AHP (Mahmoud and Alazba, 2014).

\section{3) Weighted Overlay Process}

The Weighted Overlay Process (WOP) allows the implementation of several steps in the general overlay analysis process all in one tool. It combines the following steps:

a) It reclassifies values in all input raster layers (rainfall, LULC, slope, soil) into a common evaluation scale of suitability or preference.

b) It multiplies the values of the cells in each input raster file by the raster's weight of importance.

c) It then sums the resulting values of each cell to produce the final raster file which is the suitability raster file (Udezo, 2017).

Assuming Point A in the study area of the four criteria maps used in the AHP example above have a ranking of 5 in all four maps, (i.e., the rain class as 5, LULC class 5, slope class 5 and soil class also 5) the overlay result would show 
that exact point to have a suitability of 5 (i.e., soil $-5 \mathrm{x}$ $0.0565=0.2823 \ldots$ rain $-5 \times 0.5586=2.7931)$. The final potentiality value is the sum of the resulting values for all criteria, in our example the suitability of Point $\mathrm{A}$ is 5.

The spatial distribution of the suitability map which shows the surface RWH potential was done using spatial Multi-criteria evaluation (MCE) to rank. The identification of suitable sites was considered as a multi-objective and multicriteria problem (Mahmoud and Alazba, 2014). The quantity of rainwater harvestable is given by the formula;

$Q_{a}=R_{a} \times \mathrm{A} \times \mathrm{C}$

where $Q_{a}$ is the annual harvestable rainwater, $R_{a}$ is the annual rainfall, $\mathrm{A}$ is the Area and $\mathrm{C}$ is the runoff coefficient (Maimbo et al., 2005).

\section{RESULTS AND DISCUSSION}

\section{A. Slope Map}

The slope map generated using ArcGIS is presented in Figure 2. The distribution of the slope for the study area ranged from $0^{\circ}-71.86^{\circ}$. This means there are areas with steepness as low as $0^{\circ}$ and hilly areas with steepness as high as $71.86^{\circ}$. Areas with steep slopes would allow for easy flow of water along the path while water would stagnate around areas with gentle slopes.

The slope maps were classified from $0^{\circ}-5^{\circ}, 5^{\circ}-10^{\circ}$, $10^{\circ}-19^{\circ}$ and $19^{\circ}-72^{\circ}$ (Figure 2). The slope of the area explains how rapidly water will move during the event of rains, example areas above $5^{\circ}$ will generate runoff quickly which will increase the potential for surface RWH compared to areas with slopes less than $5^{\circ}$ which will result in the increase of stagnated water (Mahmoud and Alazba, 2014).

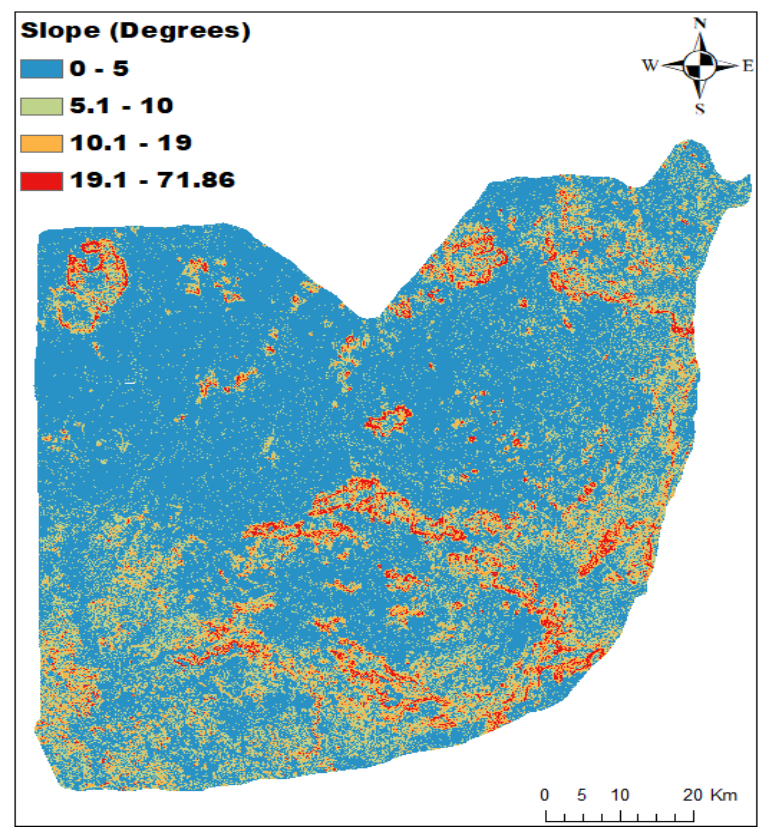

Figure 2: Slope Map for identifying surface RWH potential.

\section{B. Soil Map}

The soil data for Abuja collected from Harmonised World Soil (HWS) database showed five soil textural classes which are clay loam, sand, loamy sand, sandy clay and a predominant sandy loam as shown in Figure 3. The soil textures with a higher percentage of sand allows infiltration therefore has less runoff, while soil textures which limit infiltration will lead to more runoff.

\section{Forecasted Rainfall}

The 2046 rainfall map in Figure 4 was created with the forecasted rainfall data collected from World Bank Climate Change Portal (WBCCP) for 2046 and the 2016 rainfall map was created using satellite data from Tropical Rainfall Measuring Mission (TRMM). They highlight the changes in the precipitation between 2016 and 2046. In 2046, according to (WBCCP), the minimum rainfall in Abuja would be about $1225 \mathrm{~mm} /$ year and the maximum would be $1908 \mathrm{~mm} /$ year. The rainfall map for 2016 according to the rainfall satellite data from Tropical Rainfall Measuring Mission (TRMM) showed the minimum rainfall to be $1170 \mathrm{~mm} /$ year and the maximum was $1470 \mathrm{~mm} /$ year.

The forecasted rainfall map in Figure 4 shows 5 different ranges of the total annual rainfall for 2046 in Abuja. This shows a more precise spatial view of the rainfall interpolation in the study area (Maimbo et al., 2005). The global climate change has made it widely accepted that changes in climate will lead to intensified drought in some areas while others would experience excessive rainfall which could lead to

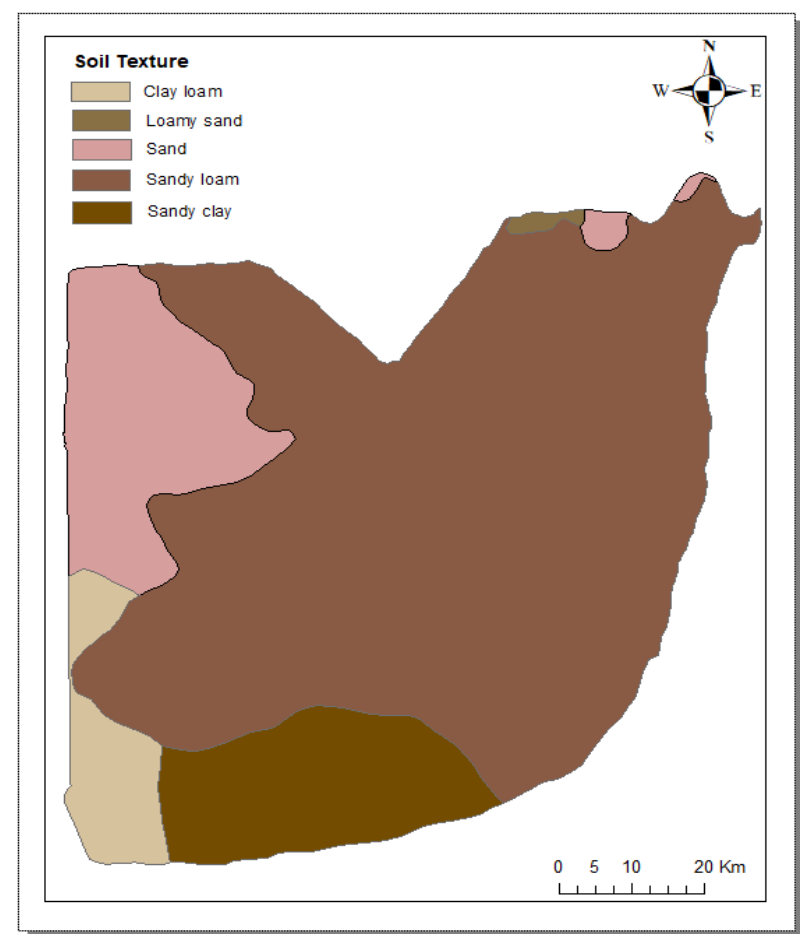

Figure 3: Soil Texture for Abuja. 


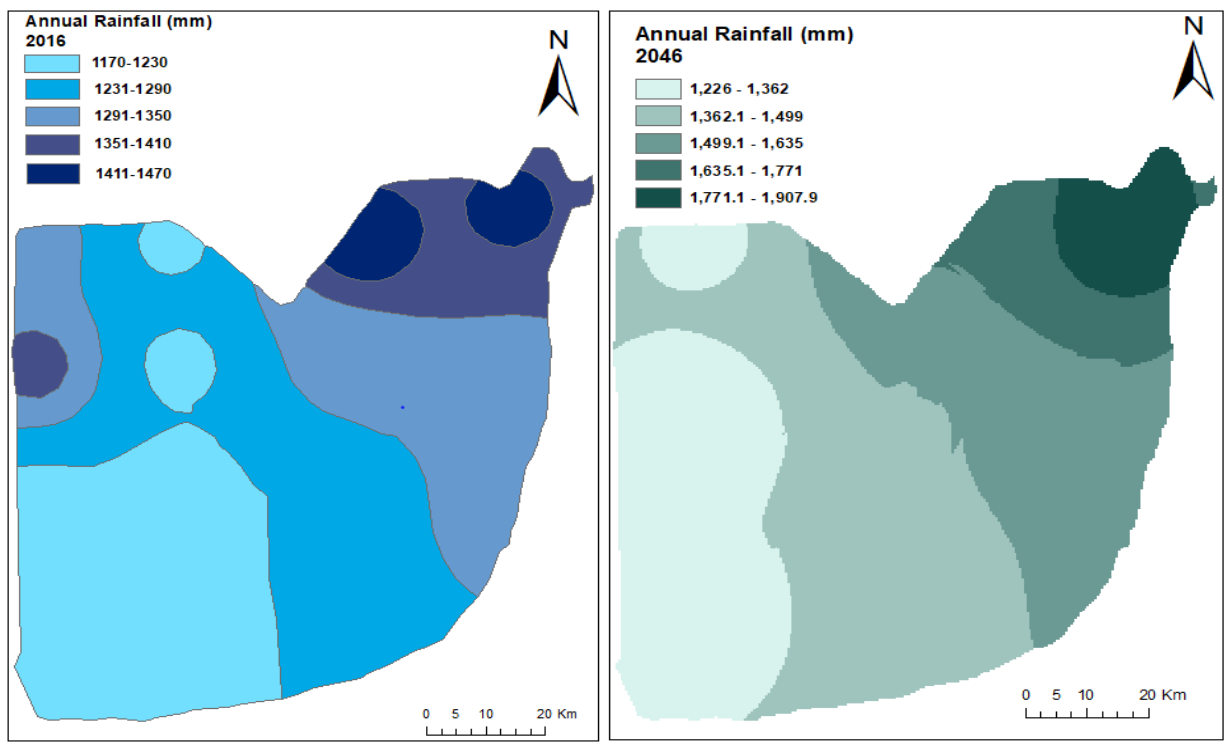

Figure 4: Abuja Rainfall maps for 2016 and 2046 respectively.

floods (Kisakye, 2018). From Figure 4, it is obvious that in total there would most likely be an increase of the annual rainfall in Abuja up till 2046 and beyond which will affect the surface RWH potential positively.

\section{Land uselland cover Map}

The LULC map for 2046 signified distinct changes in the areas occupied by each LULC class as shown in Figure 5 and Table 3.

The areas occupied by each LULC class differ in size from one year to another, some continuously increasing like built-up areas, some decreasing and others varying from one year to another as illustrated in Table 2. However, for classes like built-up areas which were seen to be continuously increasing, the explanation is obvious considering that the population is increasing massively as a result of birth rate and urbanization. The forested areas decreased between the years 2001 and 2016 due to deforestation problem in Nigeria and Abuja specifically (Adeniyi et al., 2014; Mongaby.com 2018) and so that decrease was reflected in the 2046 projection. The

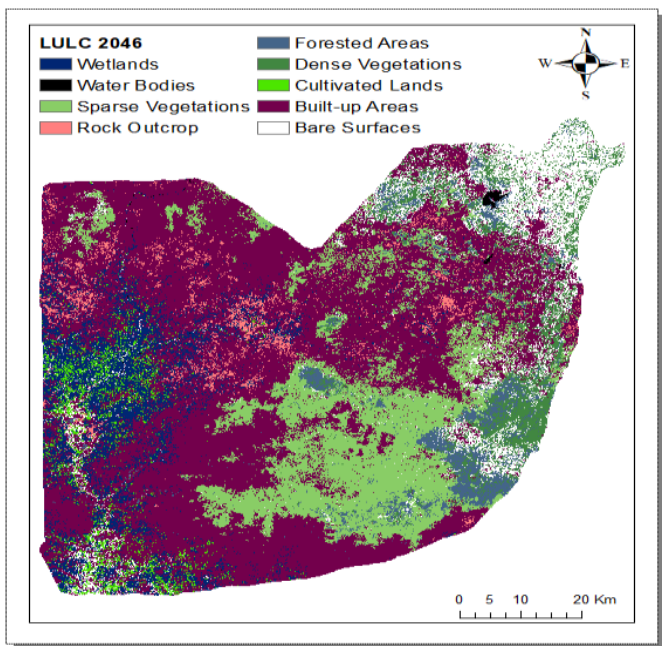

Figure 5: Projected LULC map for Abuja.
LULC classes for 2046 is shown in Figure 5, having 9 classes as the other years with which, it was predicted.

\section{A. Surface rainwater harvesting Potential for 2046}

The suitable sites for surface RWH are shown in Figure 6. Three categories were obtained in the surface RWH potential map, moderate potential, good potential and excellent potential. These categories were based on reclassification of each criterion map, the weight of each criterion and the weighted overlay of the criteria maps with a minimum ranking of 3.1 and maximum of 5 after the overlay operation. This means that every area in Abuja has at least moderate potential (i.e. 3.1 of 5 ) for surface RWH. The difference in RWH potential was based on the criteria considered, rainfall, soil texture, slope and the LULC in the areas. Some areas had less rainfall with $0^{\circ}$ slope, sandy soil texture and maybe wetlands. The area enclosed by the moderate potential region was $781.6 \mathrm{~km}^{2}$, the area enclosed by the sites with good potential was $2513.9 \mathrm{~km}^{2}$ while the sites with excellent potential enclosed the largest area of

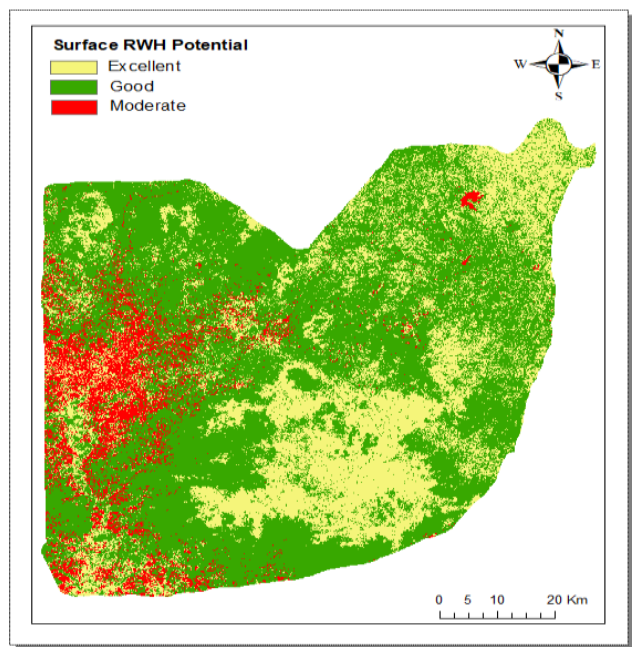

Figure 6: Surface RWH Suitability Map for 2046. 
about $4019.5 \mathrm{~km}^{2}$.

The spatial distribution showed minimum ranking to be 3.1 and maximum 5, this means that the entire study area was above the average ranking for RWH potential. These areas were classified as moderate, good and excellent adopting the classification done by Mahmoud and Alazba (2014). The percentage area enclosed by each class were estimated to be about $10.7 \%, 34.4$ and $54.9 \%$ respectively; making the whole of Abuja $100 \%$ potentially viable for surface RWH. The composite runoff coefficients for the suitable, more suitable and most suitable sites were estimated to be $0.53,0.62$ and 0.72 respectively.

Therefore, quantifying the potential of surface rainwater harvesting in terms of harvestable rainwater gave 5,840,287 $\mathrm{m}^{3}$ at minimum rainfall and at maximum rainfall $9,247,121$ $\mathrm{m}^{3}$. This water can be harvested and used for several purposes. This quantity shows that Abuja will be harvesting about $14.8 \%$ more at minimum rainfall in 2046 than the $5,087,765 \mathrm{~m}^{3}$ it would have harvested in 2016. Although every area in Abuja was found to have potential for RWH, a larger part of Abuja was found to have an excellent potential.

\section{CONCLUSION}

Identification of suitable sites for surface rainwater harvesting is an important step towards minimizing water scarcity in Abuja, Nigeria. Surface rainwater can be used to provide water for all non-potable water needs very close to where it is needed, which will reduce the stress on distribution systems and stop the over exploitation of existing and tapped water sources. The study showed within the years 2016 to 2046, the maximum annual rainfall of the state will increase from $1470 \mathrm{~mm}$ to about $1908 \mathrm{~mm}$ due to climate change.

The result showed that from 2016 to 2046, the rainwater harvesting potential will increase by about $14.8 \%$. Despite the results of the potential Abuja has for RWH, some other factors like environmental, socioeconomical and quality factors need to be carefully considered to improve the usefulness of these research findings. It is therefore recommended that further study be carried out on the environmental impact of RWH and the quality of rainwater in Abuja.

\section{ACKNOWLEDGMENT}

The authors acknowledge both the African Union Commission and Pan African University, Institute for Basic Science Technology and Innovation (PAUSTI) for their financial support to the first author towards the completion of this research.

\section{REFERENCES}

Adeniyi, T.; S. Densley and H. R. Lemu. (2014). Deforestation: FCT sits on a tighttrope. Daily Trust, City news. Accessed on March 28, 2017.

Australian Academy of Science AAS, (2018). The science of climate change. Available online at: https://www.science.org.au/learning/general- audience/science-booklets-0/science-climate-change/2-howhas-climate-changed. Accessed on March 14, 2018.

Cyblug (2016). Climate and Weather. Abuja City, Nigeria. Available online at: www.abujacity.com/abuja _and_beyond/climate-and-weather.html. Accessed on March 28, 2017.

Dongjie, G., Hidetoshi F., Weijun G., and Kazuyuki W. (2008). Land use change of Kitakyushu based on landscape ecology and Markov model. J Geogr Sci. 18:455468.

Decision Lens. (2015). Decision Lens. Retrieved from http://www.decisionlens.com. Assessed on March 12, 2018.

Eletta, O. A. A.; S. I. Mustapha; O. A. Ajayi and A. T. Ahmed. (2018). Optimization of Dye Removal from Textile Wastewater using Activated Carbon from Sawdust. Nigerian Journal of Technological Development. 15 (1): 26-32.

Food and Agriculture Organisation (FAO): Water Reports (2010). The wealth of waste: The economics of wasteater use in agriculture. Available online at: http://apps.fao.org. Assessed on April 8, 2017.

Gould, J.E., (1992). Rainwater Catchment Systems for Household Water Supply, Environmental Sanitation Reviews, No. 32, ENSIC, Asian Institute of Technology, Bangkok.

Gould, J. and Nissen-Peterson, E. (1999). Rainwater Catchment Systems for Domestic Supply: Design, Construction and Implementation. Intermediate Technology Publications, London, 335: 1999.

Huang, W.; Q. Luan; H. Liu; X. Mu and M. Bai. (2008). Monitoring urban expansion in Beijing, China by multi temporal TM and spot images. IEEE Proc, IGARSS. 4:695-698.

Intergorvenmental Panel on Climate Change (IPCC). (2007). Assessment report; Climate Change 2007 Summary for policymakers. Valencia, Spain.

Jianping, L. I.; G. Feng and Z. Bai. (2005). RS-andGIS-supported forecast of grassland degradation in southwest Songnen plain by Markov model. Geo-spatial Inf Sci. 8:104106.

Jonathan, R. B. F.; A. A. Eileen; P. J. DennedyFrank; K. Timm and M. B. Timothy. (2017). Impact of satellite imagery spatial resolution on land use classification accuracy and modeled water quality. Available online at: https://doi.org/10.1002/rse2.61. Published 20 August 2017

Kahinda, J. M.; E.S. B. Lillie; A. E. Taigbenu; M. Taute and R. J. Boroto. (2008). Developing suitability maps for rainwater harvesting in South Africa. Physics and Chemistry of the Earth 33 :788-799.

Kisakye, V.; M. Akurut and B. V. Bruggen. (2018). Effects of climate change on reliability of rainwater harvesting systems for Kabarole District, Uganda. Available online at: www,mdpi.come/journal/water.

Kogbe, C. A. (1976). Paleogeographic History of Nigeria from Albian Times. Elizabeth Publishers, Lagos, 237-252.

Logsdon, M. G.; V. F. Westerlund and J. E. Bell. (1996). Probability mapping of land use change: a GIS 
interface for visualizing transition probability. Computer Environ Urban Syst. 20:389-398.

Mahmoud, S. H., and Alazba, A. A. (2014). The potential of in-situ rainwater harvesting in arid regions: developing a methodology to identify suitable areas using GIS-based decision support system Saudi Society for Geosciences, 1-13.

Maimbo, M.; K. Elizabeth; M. Bancy; O. Alex; D. B. Tanguy; N. Meshack and V. Oduor. (2005). Mapping the potentials of rainwater harvesting in Africa. GWP-AP Series of ICRAF publications, Nairobi.

Mbilinyi, B. P.; S. D. Tumbo; H. F. Mahoo; E. M. Senkondo and N. Hatibu. (2005). Indigenous Knowledge as Decision Support Tool in Rainwater Harvesting. Physics and Chemistry of the Earth. 30: 792-798.

Mongaby.com (2018). Nigeria Environmental profile. Available online at:

https://rainforests.mongaby.com/deforestation/achive/Nigeria. htm. Assessed on April 12, 2018.

Mohamed, E.; H. Arouri; A. B. Youssef; C. Nguyenviet; M. El and H. Arouri. (2014). Effects of urbanization on economic growth and human capital formation in Africa. PGDA Working Paper No. 119: 1-23.

Muller, R. M., and Middleton, J. (1994). A Markov model of land-use change dynamics in the Niagara region, Ontario, Canada. Landscape Ecol. 9:151-157.

Odot Hydraulic Manual; available online at: http://www.oregon.gov/ODOT/GeoEnvironmental Docs/HydraulicsManual/Hydraulics-07-F.pdf.
Pacey, A., and Cullis, A. (1989). Rainwater Harvesting: The Collection of Rainfall and Runoff in Rural Areas, WBC Print Ltd., London.

Pandey, D. N., Gupta, A. K., and Anderson, D. M., (2003). Rainwater harvesting as an adaptation to climate change. Current science, 85(1): 46-59.

Rainwater Harvesting. (2006). Centre for Science and Environment.

http://www.rainwaterharvesting.org/methods/methods.htm. Accessed on April 18, 2018.

Rutherford, R. (2000). Water harvesting: An overview. Available online at: www.protos.ngo

Saaty, T. L. (1980). The analytic hierarchy process. McGraw-Hill, New York.

Stratfor Global Intelligence, (2014). Water Scarcity; Examining Impacts Around the World. STRATFOR Global Intelligence. Accessed on Februrary 8, 2018.

Udezo, N. V. (2017). Flood Vulnerability Assessment and Management for Kaduna Metropolis, Kaduna State Nigeria. M.Sc. Thesis, Department of Environmental Management, Pan African University Institute of Life and Earth Sciences, University of Ibadan, Ibadan, Nigeria.

Zhang, R.; L. Gao; W. Fan; C. Tang; H. Yuan and S. Ma. (2011). Using Markov chains to analyze changes in wetland trends in arid Yinchuan plain, China. Math Compute Modell. 54:924-930. 